\title{
Arabidopsis Clade ITGA Transcription Factors Regulate Plant Defenses in an NPR1-Independent Fashion
}

\author{
Heather L. Shearer, ${ }^{1}$ Yu Ti Cheng, ${ }^{2}$ Lipu Wang, ${ }^{3}$ Jinman Liu, ${ }^{4}$ Patrick Boyle, ${ }^{5}$ Charles Després, ${ }^{5}$ \\ Yuelin Zhang, ${ }^{4}$ Xin $\mathrm{Li}^{2,6}$ and Pierre R. Fobert ${ }^{1}$ \\ ${ }^{1}$ National Research Council Canada, 110 Gymnasium Place, Saskatoon, Saskatchewan, S7N 0W9, Canada; ${ }^{2}$ Michael \\ Smith Laboratories, University of British Columbia, Vancouver, BC, V6T 1Z4, Canada; ${ }^{3}$ Department of Biology, University \\ of Saskatchewan, 112 Science Place, Saskatoon, SK, S7N 5E2, Canada; ${ }^{4}$ National Institute of Biological Sciences, \\ Zhongguancun Life Science Park, 7 Science Park Road, Beijing 102206, P.R. China; ${ }^{5}$ Department of Biological Sciences, \\ Brock University, 500 Glenridge Avenue, St. Catharines, ON, L2S 3A1, Canada; ${ }^{6}$ Department of Botany, University of British \\ Columbia, Vancouver, BC, V6T 1Z4, Canada
}

Submitted 29 September 2011. Accepted 6 July 2012.

Transcriptional reprogramming during induction of salicylic acid (SA)-mediated defenses is regulated primarily by NPR1 (NONEXPRESSOR OF PATHOGENESIS-RELATED GENES 1), likely through interactions with TGA bZIP transcription factors. To ascertain the contributions of clade I TGA factors (TGA1 and TGA4) to defense responses, a tga1-1 tga4-1 double mutant was constructed and challenged with Pseudomonas syringae and Hyaloperonospora arabidopsidis. Although the mutant displayed enhanced susceptibility to virulent $P$. syringae, it was not compromised in systemic acquired resistance against this pathogen or resistance against avirulent $\boldsymbol{H}$. arabidopsidis. Microarray analysis of nonelicited and SA-treated plants indicated that clade I TGA factors regulate fewer genes than NPR1. Approximately half of TGA-dependent genes were regulated by NPR1 but, in all cases, the direction of change was opposite in the two mutants. In support of the microarray data, the NPR1-independent disease resistance observed in the autoimmune resistance $(R)$ gene mutant snc1 is partly compromised by tgal-1 tga4-1 mutations, and a triple mutant of clade I TGA factors with npr1-1 is more susceptible than either parent. These results suggest that clade I TGA factors are required for resistance against virulent pathogens and avirulent pathogens mediated by at least some $\boldsymbol{R}$ gene specificities, acting substantially through NPR1-independent pathways.

Sensing and defending against microbial infections are essential to the survival of all multicellular organisms. In plants, pathogens are recognized through the perception of one of two types of entities known as elicitors: microbe-associated molecular patterns (MAMPs) and effectors (Chisholm et al. 2006; Jones and Dangl 2006). Effectors, such as those delivered by

H. L. Shearer and Y. T. Cheng contributed equally to this work and are considered co-first authors.

Corresponding author: P. Fobert; Telephone: (306) 975-5587; Fax: (306) 975-4839; Email: Pierre.Fobert@nrc-cnrc.gc.ca

* The $\boldsymbol{e}$-Xtra logo stands for "electronic extra" and indicates that two supplementary figures and two supplementary tables are published online.

(C) 2012 The Crown in Right of Canada, that is, to the Government of Canada. bacterial type three secretion systems, are thought to have evolved to intercept MAMP-triggered signaling and promote pathogen growth, and can themselves be recognized by cognate host resistance $(R)$ gene products, functionally rendering them avirulent determinants. Therefore, to cause disease, adapted pathogens must suppress MAMP-triggered immunity through the deployment of effectors that are not themselves efficiently recognized by corresponding host R proteins. Plants continue to mount basal defense responses against such virulent pathogens, as demonstrated genetically through the identification of hypersusceptible mutants, sometimes referred to as an enhanced disease susceptibility (eds) phenotype (Glazebrook et al. 1996; Rogers and Ausubel 1997). A component of MAMP- and $R$-gene-mediated immunity entails the production of a mobile signal that leads to systemic acquired resistance (SAR), a broad-range disease resistance against subsequent attacks by otherwise virulent pathogens (Durrant and Dong 2004; Vlot et al. 2009).

One of the most important signaling molecules in $R$-genemediated resistance, basal resistance, and SAR is salicylic acid (SA) (Durrant and Dong 2004; Ryals et al. 1996; Vlot et al. 2009). In SA-deficient mutants such as eds5 (aka sidl, At4g39030) and sid2 (At1g74710) and in transgenic plants expressing the SA-degrading enzyme salicylate hydroxylase (NahG) that degrades SA to catechol, both $R$-gene-mediated resistance and basal defense are compromised. Exogenous application of SA or the SA analogs 2,6-dichloroisonicotinic acid (INA) and benzothiadiazol S-methyl ester (BTH) induce expression of a subset of pathogenesis-related $(P R)$ genes and resistance to pathogens.

Arabidopsis NPRI (NONEXPRESSOR OF PATHOGENESIS-RELATED GENES 1) (At1g64280) is an essential positive regulator of SA-induced $P R$ gene expression and pathogen resistance (Durrant and Dong 2004). NPRl encodes a protein containing four recognized functional domains. These include the N-terminus BTB/POZ domain and central ankyrin repeat domain, which are both protein-protein interaction motifs (Cao et al. 1997; Rochon et al. 2006; Ryals et al. 1997), as well as a C-terminus nuclear localization signal (Kinkema et al. 2000) and a novel C-terminus transactivation domain containing two oxidized cysteine residues (Rochon et al. 2006). Despite its importance to transcriptional reprogramming, NPR1 lacks known DNA-binding domains and has never been shown to bind DNA directly. However, NPR1 interacts with several members of the TGA family of DNA- 
binding basic leucine zipper transcription factors, including all clade II (TGA2 [At5g06950], TGA5 [At5g06960], and TGA6 [At3g12250]) and clade III (TGA3 [At1g22070] and TGA7 [At1g77920]) factors (Després et al. 2000; Kim and Delaney 2002; Shearer et al. 2009; Zhang et al. 1999; Zhou et al. 2000). TGA factors were originally isolated based on their ability to bind to the activating sequence 1 (as-1) element found in the Cauliflower mosaic virus $35 \mathrm{~S}$ promoter (Katagiri et al. 1989). The $a s-1$ element is a 21-bp sequence containing two TGACG binding motifs. Linker-scanning (LS) mutagenesis identified two important TGACG motifs in the Arabidopsis $P R-1$ promoter, including a positive element contributing to activation of $P R-1$ (At $2 \mathrm{~g} 14610$ ) in response to SA and INA (Lebel et al. 1998). Chromatin immunoprecipitation (ChIP) has confirmed that clade II TGA factors bind to the $P R-1$ promoter in planta, presumably on these same TGACG motifs (Johnson et al. 2003; Rochon et al. 2006). NPR1 enhances the DNA-binding activity of clade II and III TGA factors in vitro (Després et al. 2000; Shearer et al. 2009) and, together with TGA2, constitutes an SA-dependent enhanceosome capable of transactivating $P R-1$ (Rochon et al. 2006). Reverse genetics of clade II TGA factors has established that they have redundant functions and are essential for SA-induced $P R$ gene expression and pathogen resistance (Zhang et al. 2003b). The clade III factor TGA3 was shown to be required for basal resistance (Kesarwani et al. 2007) as well as a novel form of cytokinin-induced resistance (Choi et al. 2010) against the bacterial pathogen Pseudomonas syringae. The latter type of disease resistance was also shown to be dependent on NPR1 and SA. Thus, it appears that NPR1 mediates many of its effects via interactions with TGA transcription factors.

TGA factors belonging to clade I (TGA1 [At5g65210] and TGA4 [At5g10030]) do not interact with NPR1 in yeast or noninfected plant cells because of the presence of two oxidized cysteine residues in TGA1 and TGA4 (Després et al. 2003). Site-directed mutagenesis of the cysteine residues (Cys260 and Cys-266) or the reduction of these cysteines in leaves following SA-treatment enables the interaction with NPR1. Redox regulation of TGA1 and NPR1 has been proposed to be mediated by nitric oxide (Lindermayr et al. 2010). Both proteins can be $S$-nitrosylated in vitro following treatment with S-nitroglutathione (Lindermayr et al. 2010; Tada et al. 2008), resulting in the enhanced DNA binding activity of TGA1 toward its cognate target in the presence of NPR1 (Després et al. 2003). Transgenic hairpin RNA interference (RNAi) studies demonstrated that Arabidopsis TGA4 acts as a negative regulator of gene expression mediated by the as-1-like element ocs (Foley and Singh 2004), whereas virus-induced gene silencing (VIGS) indicated that a tomato orthologue of TGA1 is required for AvrPto-mediated resistance against $P$. syringae pv. tomato, which causes bacterial speck disease (Ekengren et al. 2003). Analysis of Arabidopsis T-DNA insertion alleles indicate that clade I TGA factors contribute to basal resistance against virulent $P$. syringae (Kesarwani et al. 2007; Lindermayr et al. 2010); however, the contribution of these transcription factors to resistance against other pathogens and the resistance pathways they regulate has not been clearly established.

Although mutations in NPRI abolish the SA-induced $P R$ gene expression and compromise basal resistance and SAR against virulent biotrophic pathogens, the effect of NPRI on MAMP- and $R$-gene-mediated resistance is relatively small (Liu et al. 2005; McDowell et al. 2000; Rairdan and Delaney 2002; Zipfel et al. 2004). Suppressor screening of nprl mutants revealed that constitutive activation of SSI4 and SNC1 (At4g16890), two Toll interleukin-1 receptor nucleotide-binding site leucine-rich repeat (TIR-NBS-LRR)-type R proteins, led to NPRl-independent resistance responses, suggesting the existence of NPRI-independent pathways downstream of at least some $R$ genes (Li et al. 2001; Zhang et al. 2003a). Epistasis analysis between $s n c 1$ and $e d s 5$ further supported the idea that the NPRl-independent resistance consists of both SA-dependent and SA-independent pathways. To ascertain the role clade I TGA factors play in disease resistance, we carried out reversegenetics analysis of TGAl and TGA4. Our results indicate that, whereas these TGA factors are positive regulators of disease resistance, the expression of many NPRl-dependent genes is not compromised in a tgal tga4 double mutant following treatment with SA. Subsequent epistasis analysis revealed that clade I TGA factors participate in SNC1-mediated, NPRIindependent defense responses.

\section{RESULTS}

\section{Clade I TGA factor mutants are more susceptible to $P$. syringae pv. maculicola ES4326.}

The T-DNA insertion mutants tgal-1 and tga4-1 were analyzed to determine the functions of clade I TGA factors. These mutant alleles were first reported by Kesarwani and associates (2007) and are further described in Supplementary Figure S1. Of the 10 Arabidopsis TGA bZIP transcription factors, TGAI and TGA4 share the highest degree of sequence similarity and, because previous reports indicated functional redundancies within this family (Zhang et al. 2003b), a tgal-1 tga4-1 double mutant was also obtained by crossing the single mutants and screening for the double mutant plants by polymerase chain reaction (PCR) in the $\mathrm{F}_{2}$ generation. Kinetic, reverse-transcriptase (k-RT)-PCR and Western blot analyses showed that neither gene nor their products are expressed in the tga-1 tga4-1 double mutant, indicating that the functions of TGA1 and TGA4 are abolished in the double mutant.

To test whether mutations in TGAl and TGA4 affect disease resistance, single and double mutants were challenged with $P$. syringae pv. maculicola ES4326, which is virulent on Columbia wild-type plants (Col-0). Slight increases in bacterial growth were observed in $\operatorname{tgal-1}$ or tga4-1 single mutants compared with Col-0 (Fig. 1A). Although these were occasionally found to be statistically significant in repetitions of this experiment, leaves of the tgal-1 tga4-1 double mutant consistently supported approximately 10-fold more bacterial growth than Col-0 (Fig. 1A). These differences were statistically significant, suggesting that TGAl and TGA4 perform overlapping functions, and loss of the function in both genes results in enhanced susceptibility to $P$. syringae pv. maculicola ES4326. Introducing a genomic clone of TGA1 into the double mutant rescued the enhanced disease susceptibility phenotype (Fig. 1A), demonstrating that this gene is able to complement the double mutant.

\section{Mutant tga4-1 is compromised in SAR against $P$. syringae pv. maculicola but tgal-1 and tgal-1 tga4-1 are not.}

The requirement of clade I TGA factors for SAR was tested by preinoculating two leaves per plant with an avirulent strain of P. syringae pv. tomato DC3000 (AvrRpt2). Leaves from control plants received a preinoculation with buffer only. The remaining leaves of plants in both treatments were infiltrated 2 days later with virulent $P$. syringae pv. maculicola ES4326. As observed in the enhanced susceptibility tests (Fig. 1A), double mutant plants preinoculated with buffer only (MV) harbored statistically more bacterial growth than Col-0 (Fig. 1B). However, preinoculation with $P$. syringae pv. tomato DC3000 AvrRpt2 (AV) was effective at reducing growth of virulent bacteria in the tgal-1 and tgal-1 tga4-1 mutants but not tga4-1 
(Fig. 1B), suggesting functional differences between clade I TGA factors with respect to SAR.

The tgal-1 tga4-1 mutant displays altered expression of both NPRI-dependent and NPRI-independent genes.

Previously, it was shown that clade I TGA factors interact with NPR1 after SA treatment (Després et al. 2003). To determine whether TGA1 and TGA4 function to control SA-induced gene expression, RNA was prepared from leaves of Col-0, tgal-1 tga4-1, and nprl-3 plants before and after treatment with $1.0 \mathrm{mM} \mathrm{SA}$, and analyzed using ATH1 gene chips. Differentially expressed genes were identified by two-way analysis of variance (ANOVA) using the "time" and "genotype" factors at $\alpha=0.01$, together with a fold-change of 2 (Supplementary Table S1). Consistent with published reports (Blanco et al. 2009; Pan et al. 2004; Wang et al. 2005), the abundance of a large number of gene transcripts $(n=960)$ was found be significantly different in the nprl mutant. A much smaller number of genes $(n=93)$ was found to be differentially regulated in the tgal-1 tga4-1 mutant. Of these, only 45 (49\%) were also differentially expressed in nprl-3 leaves. Among these 45 genes, the direction of change was always opposite in the two mutants: transcripts for 43 genes were downregulated in $n p r l-3$ and upregulated in tgal-1 tga4-1, whereas transcripts for two genes were upregulated in $n p r l-3$ and downregulated in tgal-1 tga4-1. Many of the genes (71\%) upregulated in tgal-1 tga4-1 relative to Col- 0 were only affected at the early 0 - and 1 -h time points and, by $8 \mathrm{~h}$ after the SA treatment, the expression levels in Col-0 and tgal-1 tga4-1 were similar.

k-RT-PCR was used to validate results from microarray hybridization with representative genes based on their expression patterns in different mutant genotypes (Fig. 2; Supplementary Fig. S2). For genes differentially expressed only in nprl-3 or in both nprl-3 and tgal-1 tga4-1, k-RT-PCR results consistently validated microarray data. For genes found to be differentially expressed by microarrays only in $\operatorname{tgal}-1 \mathrm{tga} 4-1$, results with k-RT-PCR were also consistent with their differential expression in this mutant background. However, differences in expression for these genes were occasionally noted by k-RTPCR in nprl-3. This was most obvious with PR-2 (At3g57260), a well-known NPR1-dependent gene (Cao et al. 1994) that did not meet the criteria for being differentially expressed in our microarray analyses. In most other cases, expression differences between the wild type and $n p r l-3$ by k-RT-PCR were more modest and often variable between time points in different experimental repetitions. Less than $10 \%$ of genes in this category (4/45) have been previously reported as being dependent on NPR1 (Blanco et al. 2009; Pan et al. 2004; Wang et al. 2005), consistent with our microarray results.

Genes differentially expressed in tgal-1 tga4-1 were strongly enriched for the Gene Ontology (GO) classification response to abiotic or biotic stimulus (5.8-fold, $P$ value $<4 \times 10^{-6}$ ) and response to stress $\left(5.1\right.$-fold, $P$ value $<1 \times 10^{-5}$ ). The enrichment for these $\mathrm{GO}$ terms increased when considering only genes upregulated in tgal-1 tga4-1 but downregulated in nprl-3 (5.8fold, $<1 \times 10^{-8}$ for abiotic or biotic stimulus; 13-fold, $<7.8 \times$ $10^{-7}$ for stress). Included in the stress response genes differentially expressed in tgal-1 tga4-1 are $P R-1, P R-2, P R-5$, chitinases (At2g43570 and At3g47540), and a GH3-like protein (At5g13320) involved in mediating SA accumulation and resistance to P. syringae (Jagadeeswaran et al. 2007, Nobuta et al. 2007). Known PR genes were among the highest differentially regulated genes identified in the tgal-1 tga4-1 mutant at the 1-h time point. Of the 45 genes differentially expressed in both nprl-3 and tgal-1 tga4-1, five correspond to NPR1-dependent SA-inducible genes (SAIG) reported by Blanco and associates (2009), with 1 gene being an NPR1-independent SAIG. None of the 48 genes differentially expressed only in tgal-1 tga4-1 correspond to SAIG of Blanco and associates (2009). Together, the microarray data indicate that clade I TGA factors appear to play a minor role in regulating the expression of defense responserelated genes following treatment with SA. The observation that only a small number (approximately 10\%) of NPR1-dependent genes are also regulated by clade I TGA factors suggests that these TGA factors are not important mediators of SA-triggered NPR1 function. Furthermore, the finding that approximately

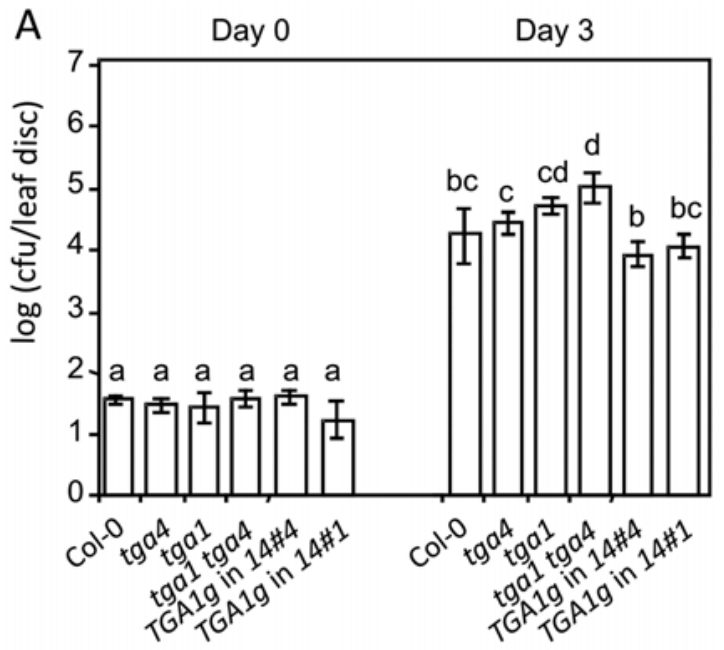

B

Day 3

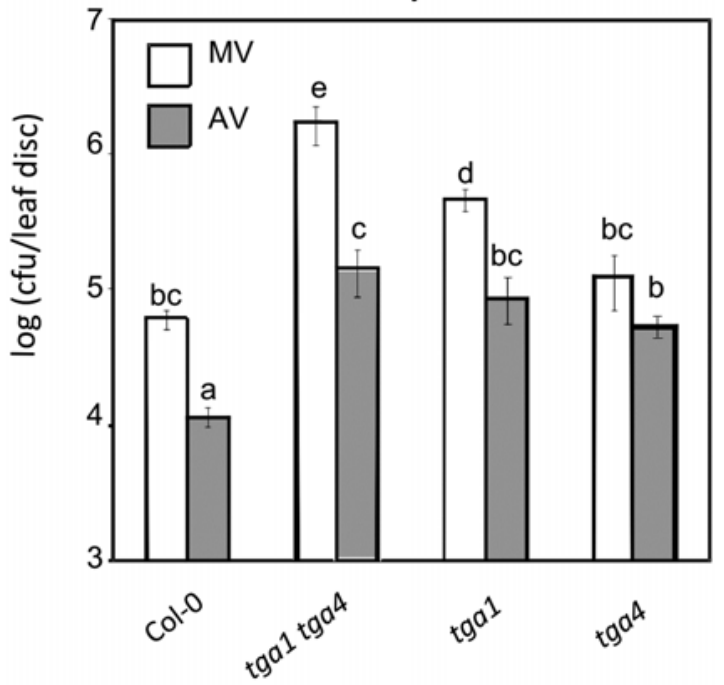

Fig. 1. Growth of Pseudomonas syringae pv. maculicola ES4326 in Col-0, tgal-1, tga4-1, tgal-1 tga4-1 double mutants, and tgal-1 tga4-1 transformed with a TGA1 genomic clone (TGA1g in 14). A, Basal resistance. BASTA-resistant $\mathrm{T}_{2}$ plants from two independent complementing lines were used for the analysis. Plants were infiltrated with a bacterial suspension at an optical density of $600 \mathrm{~nm}\left(\mathrm{OD}_{600}\right)=0.0001$. Error bars represent the standard deviation of four replicates. An analysis of variance (ANOVA) of the log-transformed data was performed at $\alpha=0.01$; treatments with common letters over the error bars are not significantly different from each other. This experiment was repeated twice, with similar results. B, Systemic acquired resistance. Growth of $P$. syringae pv. maculicola ES4326 in 4-week-old plants of the indicated genotypes. Plants were preinoculated with either $P$. syringae pv. tomato DC3000 AvrRpt2 $\left(\mathrm{OD}_{600}=\right.$ 0.001 ) in $10 \mathrm{mM} \mathrm{MgCl}_{2}$ (AV, gray bars) or with $10 \mathrm{mM} \mathrm{MgCl}_{2}$ alone (mock; MV, white bars), and remaining leaves were inoculated 2 days later with $P$. syringae pv. maculicola ES4326 $\left(\mathrm{OD}_{600}=0.0001\right)$. Bars represent the standard error of eight replicates. An ANOVA of the log-transformed data was performed at $\alpha=0.01$; treatments with common letters over the error bars are not significantly different from each other. This experiment was repeated four times, with similar results. 
$50 \%$ of the genes regulated by clade I TGA factors are not differentially expressed in the nprl mutant indicates that clade I TGA factors act, at least in part, independently of NPR1.

Unlike npr1 mutants, clade I TGA factor mutants express high levels of $P R$ genes after pathogen challenge and are not hypersensitive to exogenous SA.

Although SA signaling is an important mediator of plant defense responses against biotrophic pathogens, transcriptional responses triggered by pathogen challenge are determined by multiple signaling inputs that rely on several plant growth regulators (Robert-Seilaniantz et al. 2011). To ascertain whether clade I TGA factors contribute to SA-dependent gene expression following pathogen challenge, $P R-1$ transcript levels were quantified in leaves of Col-0 and tgal-1 tga4-1 mutant plants infiltrated with virulent or avirulent $P$. syringae pv. tomato DC3000 (Fig. 3A and B). As observed in the SA treatment, levels of $P R-1$ in the tgal-1 tga4-1 mutant were higher than in Col-0 prior to infection, although the difference was not as pronounced. Levels continued to be slightly higher in tgal-1 tga4-1 at early time points following infiltration; however, at later time points, similar levels were detected in the wild type and mutant. Similar results were observed with other markers of the SA-mediated defense response, including $P R-2$ and $P R-5$ (At1g75040) (data not shown). Thus, loss of clade I TGA factors does not compromise the expression of SA-inducible $P R$ genes following pathogen challenge.
Seedlings lacking NPR1 or clade II TGA factor function are hypersensitive to the toxic effects of high concentrations of SA (Cao et al. 1997; Zhang et al. 2003b). To further explore the interactions of clade I TGA factors with SA signaling, we tested whether these mutants were also altered in this regard. Whereas nprl-1 and the tga2-1 tga5-1 tga6-1 triple-mutant plants bleached in the presence of $0.2 \mathrm{mM} \mathrm{SA}$, all three clade I TGA factor mutant combinations remained green (Fig. 3C), suggesting that TGA1 and TGA4 are not required for the regulation of tolerance to SA. The tgal-1 tga4-1 double mutant also displayed developmental abnormalities not observed in either nprl or clade II mutants, including severe leaf curling (Fig. 3D).

\section{The tga1-1 tga4-1 double mutation blocks the constitutive pathogen resistance in snc1 npr1-1 mutant plants.}

Arabidopsis SNCl encodes a TIR-NBS-LRR type of R protein (Zhang et al. 2003a). In the sncl nprl-1 mutant plants, a gain-of-function mutation in SNC1 leads to constitutive activation of NPRI-independent disease resistance. Because microarray analysis revealed substantial differences in gene expression patterns between clade I TGA factors and NPR1, we sought to determine whether these TGA factors function in the SNC1mediated, NPR1-independent resistance pathway. The sncl nprl-1 tgal-1 tga4-1 quadruple mutant was generated by crossing sncl nprl-1 and tgal-1 tga4-1 plants and tested for resistance against $P$. syringae pv. maculicola ES4326. The sncl

A
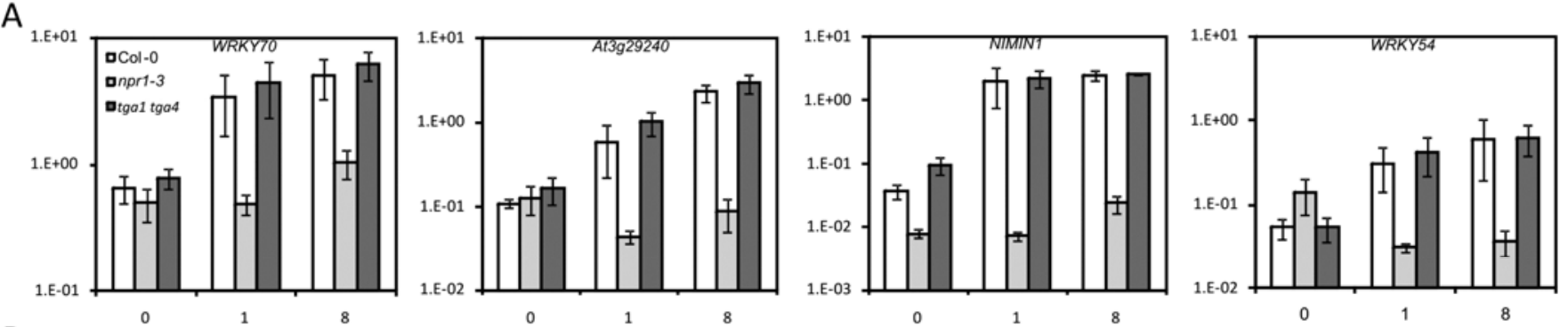

B
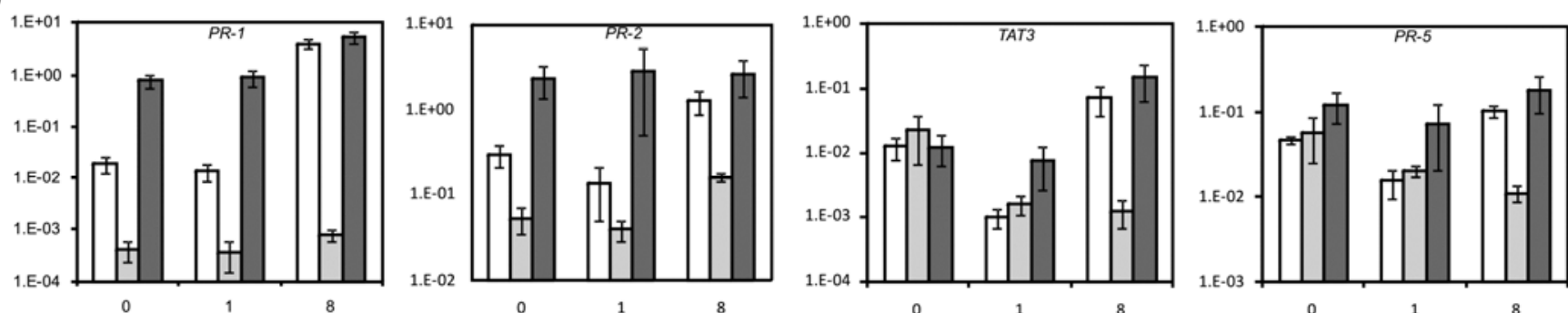

C
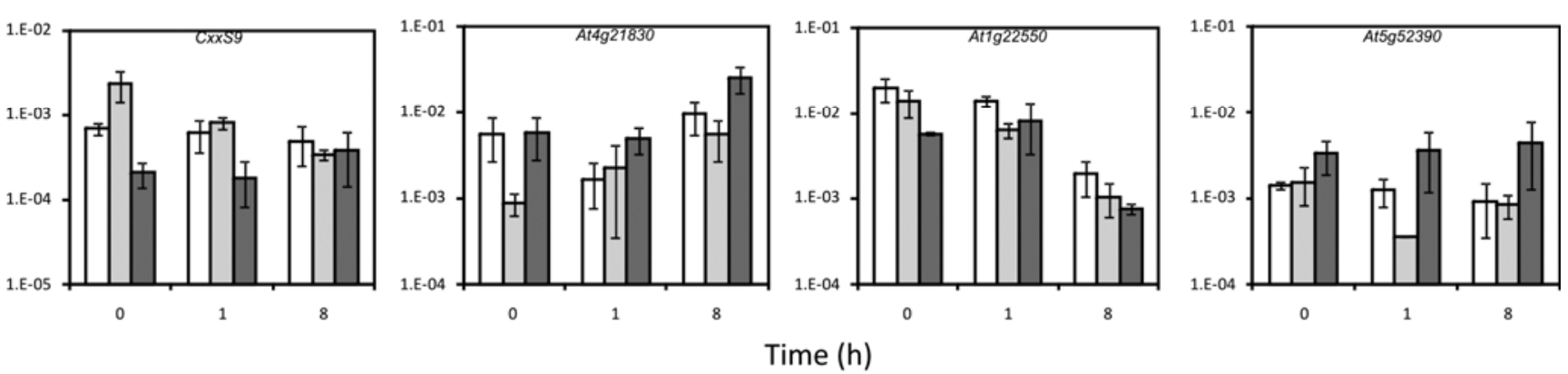

Fig. 2. Kinetic reverse-transcriptase polymerase chain reaction (k-RT-PCR) validation of microarray results. Based on microarray results, at least four representative members for each pattern of gene expression in different mutants were analyzed by k-RT-PCR. Values represent the average of three biological replicates, each containing leaves from nine plants, normalized to the expression of UBIQUITIN5. Error bars represent \pm standard error. The experiment was repeated at least twice, with similar results. A, NPR1 (NONEXPRESSOR OF PATHOGENESIS-RELATED GENES 1)-dependent genes not influenced by TGA1 or TGA4; B, genes with increased expression in tgal-1 tga4-1 and decreased expression in $n p r 1-3$; C, genes differentially regulated in tgal-1 tga4-1 but not nprl-3. 
nprl-1 tgal-1 tga4-1 plants support 10-fold more bacterial growth than sncl nprl-1 (Fig. 4A), indicating that the NPRlindependent resistance was partially blocked by the tgal-1 tga4-1 double mutation.

\section{A tga1-1 tga4-1 npr1-1 triple mutant is more susceptible to $P$. syringae pv. maculicola ES4326 than npr1-1.}

To further confirm whether TGAI and TGA4 function in parallel with NPR1, we also generated the tgal-1 tga4-1 nprl-1 triple mutant and tested it against $P$. syringae pv. maculicola ES4326. The tgal-1 tga4-1 nprl-1 plants support higher bacterial growth than the nprl-1 single mutant and the tgal-1 tga4-1 double mutant (Fig. 4B), indicating that the enhanced disease susceptibility phenotype in tgal-1 tga4-1 and $n p r l-1$ is additive and the function of TGAl and TGA4 in disease resistance is at least partly independent of NPRI.

\section{The tgal-1 tga4-1 npr1-1 triple mutant exhibits enhanced susceptibility to Hyaloperonospora arabidopsidis Emwa1.}

We also tested the tgal-1 and tga4-1 single and double mutants against the oomycete pathogen Hyaloperonospora arabi- dopsidis Emwa1. In Col-0, resistance against $H$. arabidopsidis Emwal is specified by the resistance gene RPP4. The tgal-1 tga4-1 double mutant is no more susceptible to H. arabidopsidis Emwa1 than either Col-0 or the single mutants (Fig. 5). However, combining tgal-1 tga4-1 and nprl-1 led to a dramatic increase in susceptibility to $H$. arabidopsidis Emwa1. Because the tgal-1 tga4-1 nprl-1 triple mutant is more susceptible to $H$. arabidopsidis Emwal than tgal-1 tga4-1 and nprl-1 mutation alone, the compromised resistance to $H$. arabidopsidis Emwal is likely caused by the additive effect of mutations in TGA1, TGA4, and NPR1, further suggesting that $T G A 1$ and TGA4 function in an NPRl-independent resistance pathway.

\section{DISCUSSION}

Current models posit that the nuclear function of NPR1 is mediated predominantly through its interactions with TGA transcription factors (Durrant and Dong 2004; Rochon et al. 2006). Although the contribution of NPR1 to defense responses has been well characterized, the corresponding roles of TGA factors are only now being elucidated through reverse genetic
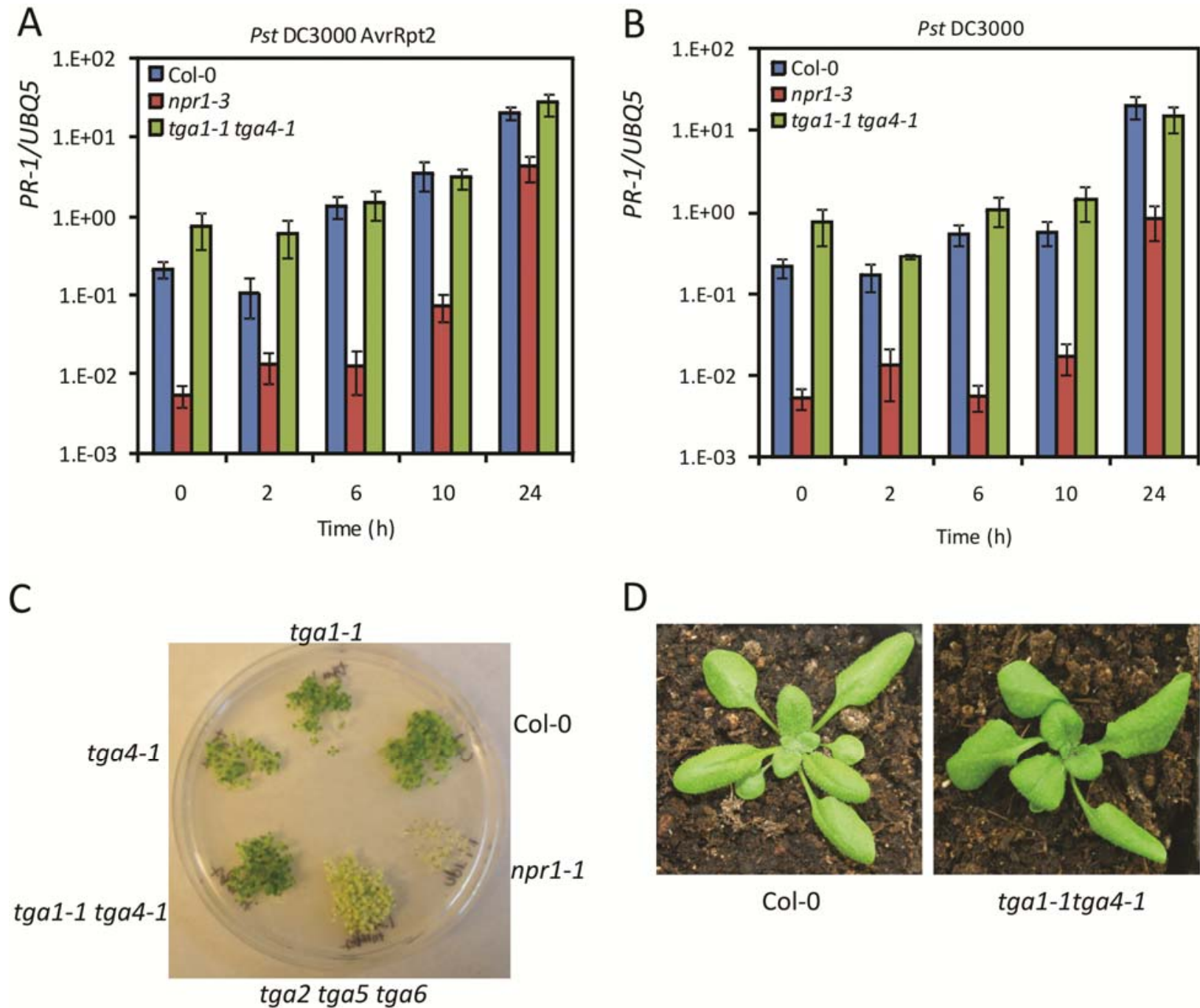

$\mathrm{D}$

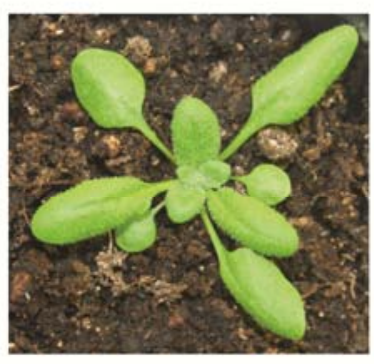

Col-0

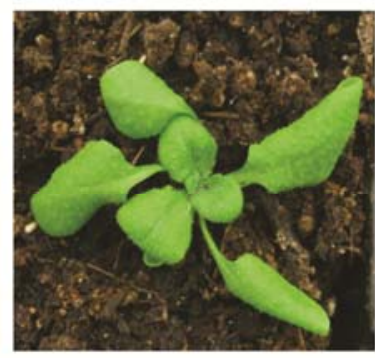

tga1-1tga4-1

Fig. 3. Gene expression and phenotypic analysis of the tgal tga4 double mutant. A and $\mathbf{B}$, Kinetic reverse-transcriptase polymerase chain reaction analysis of PR-1 expression in Col-0, npr1-3, and tgal-1 tga4-1 rosette leaves following infiltration with A, avirulent Pseudomonas syringae pv. tomato DC3000 AvrRpt2 or B, virulent $P$. syringae pv. tomato DC3000 at $\mathrm{OD}_{600}=0.001$. Values were normalized to the expression of UBIQUITIN5 and represent the average of three biological replicates, each containing leaves from nine plants, \pm standard error. C, Analysis of the tolerance of Col-0, nprl-1, tgal-1, tga4-1, tgal-1 tga4-1, and tga2-1 tga5-1 tga6-1 plants to high levels of salicylic acid (SA). Seed were plated on Murashige and Skoog medium containing 0.2 mM SA and the photographs were taken 10 days after germination. D, Three-week-old plants grown in soil, with the tgal-1 tga4-1 mutant displaying a leaf curling phenotype. 
studies (Choi et al. 2010; Kesarwani et al. 2007; Lindermayr et al. 2010; Zander et al. 2010; Zhang et al. 2003b). Results presented herein indicate that clade I TGA factors are unlikely to be major mediators of NPR1 during plant defense responses and, in fact, that the function of clade I TGA factors is substantially independent of NPR1.

NPR1 has been implicated in several different types of disease resistance responses. Particularly well studied are interactions of nprl mutants with virulent races of $P$. syringae and $H$.
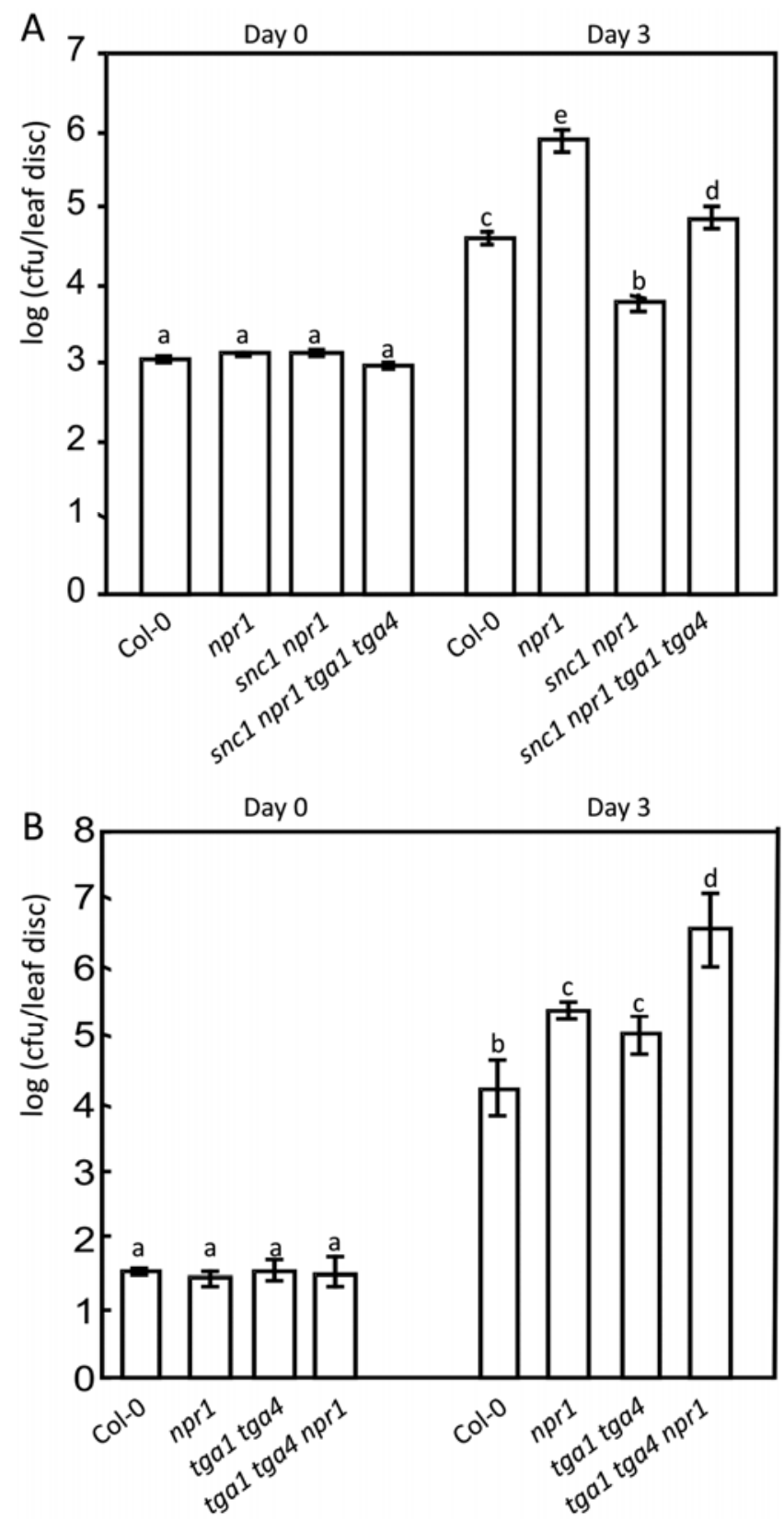

Fig. 4. Epistatic analysis of clade I TGA factors, NPR1 (NONEXPRESSOR OF PATHOGENESIS-RELATED GENES 1), and SNC1. Plants were infiltrated with a bacterial suspension at an optical density of $600 \mathrm{~nm}=$ 0.0001. Error bars represent the standard deviation of four replicates. An analysis of variance of the log-transformed data was performed at $\alpha=$ 0.01 ; treatments with common letters over the error bars are not significantly different from each other. This experiment was repeated at least twice, with similar results. A, Growth of Pseudomonas syringae pv. maculicola ES4326 in Col-0 and mutant combinations involving clade I TGA factors, nprl-1, snc1 nprl-1, and sncl nprl-1 tgal-1 tga4-1 plants. B, Growth of $P$. syringae pv. maculicola ES4326 in Col-0, npr1-1, tgal-1 tga4-1, and npr1-1 tgal-1 tga4-1 plants. arabidopsidis, before and after elicitation of SAR (Durrant and Dong 2004). We assumed that, if clade I TGA factors played an important role in mediating NPR1 function, the tgal-1 tga4-1 double mutant would be similarly affected in its interactions with these pathogens. Our results confirm previous findings (Kesarwani et al. 2007; Lindermayr et al. 2010) that clade I TGA factors are required for resistance against virulent P. syringae (Fig. 1). We also provide data demonstrating that the tgat1-1 tga4-1 double mutant is not compromised in SAR against this bacterial pathogen (Fig. 1B). These results are consistent with a role for clade I TGA factors in basal defense but not SAR. Interestingly, clade II TGA factors have been reported to have a complementary phenotype; compromised in SAR but not basal defense (Zhang et al. 2003b). The two clades of TGA factors also differ in their response to high levels of SA, with clade II TGA factors behaving similarly to NPR1 (Fig. 3C). Thus, whereas available information suggests that there is considerable functional overlap within clades of TGA factors, it seems that there is functional specialization between clades, with different clades possibly responsible for specific aspects of NPRl function.

Although both tgal-1 and the tgal-1 tga4-1 double mutant displayed SAR, tga4-1 did not (Fig. 1B). These observations indicate that the functions of TGA1 and TGA4 are not fully redundant and suggest the possibility of a more complex interaction between clade I TGA factors. This may also be true for clade II TGA factors. The tga 2 tga 5 tga6 triple mutant is compromised in SAR and SA-induced $P R-1$ gene expression (Zhang et al. 2003b); however, results with the single tga2-2 mutant (Kesarwani et al. 2007) and TGA5-overexpressing plants (Kim and Delaney 2002) indicate that these TGA factors act as negative regulators of SA-induced $P R$ gene expression. Thus, TGA2 function appears to be modified by the presence or absence of other clade II TGA factors (Kesarwani et al. 2007). Curiously, the TGA5-ovexpressing plants of Kim and Delaney (2002) were designed to suppress this TGA factor through antisense technology but, instead, yielded increased steady-state levels of TGA5 through an unknown mechanism.

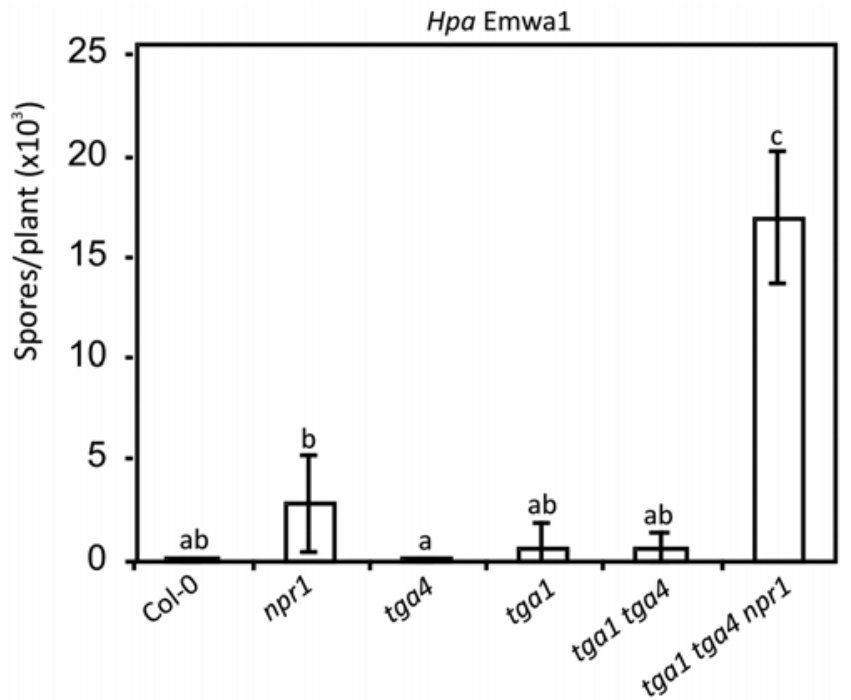

Fig. 5. Growth of Hyaloperonospora arabidopsidis EMWA1 on Col-0, npr1-1, tga1-1, tga4-1, tga1-1 tga4-1, and tga1-1 tga4-1 npr1-1 plants. Each treatment contains four replicates, and the numbers represent the average spore counts per plant. Error bars represent the standard deviation of four replicates. An analysis of variance was performed at $\alpha=0.01$; treatments with common letters over the error bars are not significantly different from each other. This experiment was repeated twice, with similar results. 
Even though both the tgal tga4 double mutant and nprl are more susceptible to virulent $P$. syringae, epistasis analyses revealed that they act, at least partly, in different pathways. Combining tgal-1 tga4-1 mutations with nprl-1 or nprl-1 and sncl resulted in increased susceptibility to $P$. syringae pv. maculicola ES4326 (Fig. 4). Although neither tgal-1 tga4-1 nor $n p r l-1$ are affected in resistance to $H$. arabidopsidis Emwa1, the triple tgal-1 tga4-1 nprl-1 mutant is susceptible (Fig. 5). In addition, enhanced resistance observed in the $s n c 1$ mutant has previously been shown to be mostly independent of NPR1 (Zhang et al. 2003a). Thus, increased susceptibility of the tgal-1 tga4-1 nprl-1 sncl quadruple mutant compared with $n p r 1-1$ sncl suggests that clade I TGA factors function as part of one or more of these NPR1-independent pathways.

NPR1 independence of clade I TGA factors is also supported by our transcript profiling results, which show that approximately half of the TGA1- and TGA4-regulated genes are not differentially regulated in the $n p r l$ mutant, before or after treatment with SA, and, thus, are unlikely to be under the control of NPR1. If the function of clade I TGA factors was exclusively dependent on NPR1, one would expect genes affected by mutation of these factors to compose a subset of those regulated by NPR1, as was reported for the transcription factor WRKY18 (At4g31800) and NPR1 (Wang et al. 2006). Although some genes classified as being differentially regulated only in tgal-1 tga4-1 by microarray analysis displayed changes in expression between nprl-3 and the wild type by k-RT-PCR (Fig. 2), these changes tended to be inconsistent between experimental repetitions. Accordingly, we believe that most of the differences observed by k-RT-PCR only are unlikely to be of biological significance. However, models used for microarray analysis focus on controlling type I errors (false positives) and it is likely that the dataset excludes genes that are truly differentially expressed in the npr 1-3 mutant (type II errors; false negatives). An example of this would be $P R-2$. We believe that our classification is generally accurate, given that fewer than $10 \%$ of the genes in question have been reported to be dependent on NPR1 (Blanco et al. 2009; Pan et al. 2004; Wang et al. 2005).

Additionally, for genes differentially expressed in both tgal-1 tga4-1 and npr 1-3, the direction of change compared with the wild type was always opposite. Levels of several defense-related genes, including $P R-1, P R-2$, and $P R-5$, are dramatically reduced in nprl-3 but constitutively elevated in the tgal-1 tga4-1 mutant (Figs. 2 and 3). By $8 \mathrm{~h}$ after SA treatment or $24 \mathrm{~h}$ following pathogen challenge, the expression of these genes has returned to wild-type levels in tgal-1 tga4-1. Lindermayr and associates (2010) reported similar findings in nonelicited material. These observations are consistent with a role for clade I TGA factors as repressors of defense gene expression in the absence of elicitation. A similar function was proposed for clade II TGA factors (Zhang et al. 2003b) and confirmed biochemically for TGA2 by Rochon and associates (2006).

Unlike clade II TGA factors (Zhang et al. 2003b), clade I factors do not appear to be required for SA-induced gene expression, because transcript levels of very few genes, including well-known SA-pathway marker genes, are reduced in tgal-1 tga4-1 following misting with this plant hormone (Fig. 2). In addition to SA, levels of several plant growth regulators have been shown to change in response to pathogen challenge, with the resulting signals being integrated by the plant cell to generate appropriate defense responses (Robert-Seilaniantz et al. 2011). Although it remains possible that such hormonal crosstalk following pathogen challenge compromised the expression of some defense genes in the tgal-1 tga4-1 mutant, k-RTPCR analysis confirmed that transcripts for SA-pathway marker genes, including $P R-1, P R-2$, and $P R-5$, continue to accumulate at or above wild-type levels following challenge with virulent and avirulent $P$. syringae pv. tomato DC3000 (Fig. 3A and B; data not shown).

The uncoupling of disease resistance and SA-dependent $P R$ gene expression, as observed in the tgal-1 tga4-1 mutant, although unusual, has been previously reported. For example, Clarke and associates (1998) reported that the cpr6 nprl double mutant was compromised in resistance against virulent $P$. syringae pv. maculicola ES4326 despite expressing SAmarker genes. Conversely, transgenic overexpression of TGA5 resulted in substantially less $P R-1$ transcript accumulation following pathogen challenge or elicitation with the SA analog INA, yet the plants displayed enhanced resistance to virulent H. arabidopsidis (Kim and Delaney 2002). Reduced apoplastic PR-1 protein accumulation in Nicotiana benthamiana mediated by VIGS of a PM syntaxin also failed to compromise resistance against a virulent strain of $P$. syringae (Kalde et al. 2007). The above findings suggest the existence of novel defense pathways leading to the production of unidentified antibacterial gene products or barriers. These would appear to include both NPR1-dependent events, as reported for the cpr6 nprl mutant (Clarke et al. 1998), and NPR1-independent events, as observed in the TGA5 overexpressors (Kim and Delaney 2002) and the tgal-1 tga4-1 mutant.

Clade I TGA factors have been shown to physically interact with NPR1 in planta following SA treatment (Després et al. 2003). This suggests that they may co-regulate sets of genes. Based on our findings and the current literature, one possibility is that, in nonelicited cells, clade I TGA factors, unbound to NPR1, act to repress gene expression. Following challenge with biotrophic pathogens, redox-mediated post-translational modification of either TGA1 and TGA4 (Després et al. 2003; Lindermayr et al. 2010) or NPR1 (Mou et al. 2003; Tada et al. 2008) facilitates interaction between the proteins, relieving repression. Because only approximately $10 \%$ of genes differentially regulated in nprl-3 are affected in tgal-1 tga4-1, the above scenario would occur at only a subset of NPR1-dependent genes. Also, because transcript levels of NPR1-dependent genes are not compromised in tgal-1 tga4-1 at later times following elicitation, we postulate that their expression is regulated by NPR1 acting through other clades of TGA factors or other classes of transcription factors.

We routinely observed increased steady-state levels of $P R-1$ in nonelicited leaves of the tgal-1 tga4-1 mutant compared with the wild type. However, the magnitude of these increases was variable between experiments. Although several measures were undertaken to minimize biological variation, including the use of sample pooling and replication, and we strove to maintain very similar growth conditions throughout the course of this study, it is possible for small environmental changes to cause large differences in gene expression (Clarke and Zhou 2006). An alternative scenario is that loss of clade I TGA factors results in an unstable chromatin environment at the $P R-1$ locus in the absence of elicitation, and is prone to variation in gene expression. Regardless of the source of this variation, levels of $P R-1$ were never observed to be lower in the tgal-1 tga4-1 mutant than in the wild type, under either nonelicited or elicited conditions.

Although we have been unable to conclusively identify what processes are represented by the set of genes controlled by clade I TGA factors, the developmental defects in the tgal-1 tga4-1 double mutant, as well as our observations that this mutant is delayed in flowering (data not shown), lead us to speculate that they may include aspects of cell wall organization, cell division, and transition to flowering. Consistent with this notion, TGA4 has recently been shown to physically interact with CONSTANS, a key regulator of flowering time (Song et al. 2008). Neither nprl nor clade II TGA factor mutants dis- 
play overt developmental defects. However, NPR1 has been implicated in cell growth and division (Vanacker et al. 2001), and mutation of distantly related members of both the NPR1 and TGA families, including BOP1 and BOP2 (Hepworth et al. 2005), PAN (Chuang et al. 1999), and TGA9 and TGA10 (Murmu et al. 2010) display clear growth and developmental abnormalities. None of the BOP, PAN, or TGA9 or TGA10 factors have been implicated in disease resistance. In contrast, clade I TGA factors appear to be unique in mediating both defense responses and developmental processes. Whether and how the developmental aspects of clade I mutants contribute to disease resistance remains to be determined.

\section{MATERIALS AND METHODS}

\section{Biological materials.}

All Arabidopsis thaliana plants used in this study were in the ecotype Col-0 genetic background. The tgal-1 and tga4-1 single mutants (Salk_028212 and Salk_127923, respectively) were generated by the Salk Institute Genome Analysis Laboratory project (Alonso et al. 2003) and obtained from the Arabidopsis Biological Resource Center (Columbus, OH, U.S.A.). The location of the T-DNA insertion was confirmed by sequencing of PCR fragments. Plants homozygous for the T-DNA insertions were identified by PCR. The tgal-1 tga4-1 double mutant was obtained through genetic crosses of the single mutants and screening $\mathrm{F}_{2}$ by PCR. The quadruple mutant tgal-1 tga4-1 sncl nprl-1 and triple mutant tgal-1 tga4-1 nprl-1 were obtained from a cross between tgal-1 tga4-1 and sncl npr 1-1. Double, triple, and quadruple mutants were identified in the $\mathrm{F}_{2}$ generation by genotyping with PCR. To create the TGA1 complementation line (TGAlg in tgal tga4), a genomic copy of TGAl was isolated by PCR using primers TGA1-Pro$5^{\prime}$ (CGGGGTACCTATGTCTCCTATGGAGCCTG) and TGA13'-BamHI (CGCGGATCCAGAGTTCTCACTCTCGAGCG), and inserted into the vector pGreen229 (Hellens et al. 2000). Introduced restriction sites used in cloning are underlined. The Agrobacterium-mediated floral dip method was used to transform tgal tga4, and transformants were selected using Basta (Clough and Bent 1998). All other materials, including tga2-1 tga5-1 tga6-1, npr1-1, npr1-3, and nprl-1 sncl mutants, have been previously described (Cao et al. 1994; Glazebrook et al. 1996; Li et al. 2001; Zhang et al. 2003b). Although two NPRI mutant alleles were used in this study, available information indicates that these behave similarly with respect to disease resistance and gene expression in our hands. The npr $1-1$ allele was favored for genetic analyses, because the $s n c l$ mutant is in this background ( $\mathrm{Li}$ et al. 2001). The nprl-3 allele was used for gene expression and associated protein-based analyses because it contains a $\mathrm{C}$-terminal deletion against which a polyclonal antibody was generated (Després et al. 2000).

\section{Pathogen infections.}

For basal resistance tests, plants were grown at $22^{\circ} \mathrm{C}$ under cycles of $16 \mathrm{~h}$ of light and $8 \mathrm{~h}$ of darkness. Infection of plants with $P$. syringae pv. maculicola ES4326 and H. arabidopsidis Emwa1 was carried out as previously described (Li et al. 2001). For Hyaloperonospora sp. infections, 2-week-old seedlings were sprayed with $H$. arabidopsidis Emwal at a concentration of 50,000 zoospores/ml of water. After 7 days of incubation under $90 \%$ humidity and cycles of $16 \mathrm{~h}$ of day and $8 \mathrm{~h}$ of night, five plants were randomly harvested into $1 \mathrm{ml}$ of water, and spores on the plants were vortexed off and counted using a hemocytometer.

For SAR tests, seed were surface sterilized and germinated on $1 \times$ Murashige and Skoog medium (Sigma-Aldrich, St. Louis) as previously described (Liu et al. 2005), except that phytagel (Sigma P-8169) at $4.5 \mathrm{~g} /$ liter was used as the gelling agent and plates were sealed with micropore tape $(3 \mathrm{M}, \mathrm{St}$. Paul, MN, U.S.A.). Soil- and medium-grown plants were maintained at $70 \%$ relative humidity, under $150 \mu \mathrm{E}$ cool-white fluorescent lights, with a $10-\mathrm{h}, 21^{\circ} \mathrm{C}$ light period and a $19^{\circ} \mathrm{C}, 14-\mathrm{h}$ dark period. At 7 or 8 days postgermination, seedlings were transplanted to 72-cell flats of Sunshine mix number 4 (Sun Gro, Bellevue, WA, U.S.A.). Infection of plants was generally performed according to Liu and associates (2005), with the following modifications. The abaxial side of two leaves from 3-week-old plants were syringe infiltrated with $10 \mathrm{mM} \mathrm{MgCl}_{2}$ or a suspension of the avirulent strain $P$. syringae pv. tomato DC3000 (AvrRpt2) (optical density at $600 \mathrm{~nm}\left[\mathrm{OD}_{600}\right]=0.001$, equivalent to $1 \times 10^{6} \mathrm{CFU} \mathrm{ml} \mathrm{m}^{-1}$ ). Two days later, four remaining leaves were syringe infiltrated with virulent $P$. syringae pv. maculicola $4326\left(\mathrm{OD}_{600}=0.0001 ; 1 \times 10^{5} \mathrm{CFU} \mathrm{ml}{ }^{-1}\right)$ and samples were collected 3 days later. The average number of $\mathrm{CFU}$ per leaf disc was calculated and log-transformed data were analyzed statistically using ANOVA, General Linear Model, as implemented in the SAS software package (SAS Institute Inc., Cary, NC, U.S.A.). All bacterial disease tests were performed in parallel at two separate research institutes with similar results. For k-RT-PCR analysis of $P R-1$, all leaves large enough to manipulate at 25 days postgermination were infiltrated in a random order with either virulent $P$. syringae pv. tomato DC3000 at $1 \times 10^{6} \mathrm{CFU} \mathrm{ml}{ }^{-1}$ or the same titer of avirulent $P$. syringae pv. tomato DC3000 (AvrRpt2), as previously described (Liu et al. 2005).

\section{Microarray analysis.}

Plants (Col-0, nprl-3, and tgal-1 tga4-1) were grown as for the SAR test, except that seedlings were transplanted to Bell's potting soil (Early's Farm \& Garden Centre, Saskatoon, SK, Canada). Twenty-five days postgermination, 8 and $1 \mathrm{~h}$ prior to harvest, flats were thoroughly misted with either water or a solution of $1 \mathrm{mM}$ SA (Sigma-Aldrich), covered, and returned to the growth cabinet. Whole leaves, not including the petiole, were harvested into liquid nitrogen between 75 and 45 min before the end of the light cycle. RNA was extracted as described below, with each replicate representing RNA extracted from nine individual plants. This experiment was repeated three times and pooled samples from each of the repeats were hybridized separately to microarrays.

Hybridization to Affymetrix ATH1 chips was performed by the Affymetrix Genechip Facility at the University of Toronto, ON, Canada. A MAS5.0 normalization using a target value of 500 was performed, followed by gcRMA normalization in GeneSpring 7.3.1 software (Agilent Technologies, Santa Clara, CA, U.S.A.). All subsequent analyses of the data were performed using GeneSpring software. To generate the list of differentially expressed genes, a two-way ANOVA was performed using the time and genotype factors. Multiple correction factors (e.g., Benjamini-Hochberg or Bonferroni) were not applied in this analysis because their use assumes independence of loci, which may not be appropriate for gene expression data and can reduce statistical power but increase the occurrence of type II errors to unacceptable levels (Robinson and Parkin 2008). Indeed, visual inspection of our microarray data with previous work (Pan et al. 2004; Wang et al. 2005) and our own k-RTPCR validation of the microarray results indicated that many interesting genes were being excluded when these corrections were used, clearly indicating an unacceptable level of falsenegative calls. Therefore, we chose a more stringent cut-off of $\alpha=0.01$, together with a fold-change (for at least one time point) of 2 but did not apply a correction to the ANOVA. Lists of genes with significant genotype or time-genotype effects were generated, and the overlapping genes between lists were 
identified. Implicit in this design, genes listed needed to be differentially expressed at a minimum of one time point. Expected frequencies of GO terms in lists were based on TAIR GO annotations as calculated by the Classification SuperViewer tool (Provart and Zhu 2003), available at the Bio-Array Resource website. A significance cut-off of $\alpha=0.05$ and a fold-over-representation cut-off of 1.5 were used to generate this list of over-represented GO-categories. TGA1, TGA4, and NPRI were excluded from the analysis.

\section{k-RT-PCR analysis.}

Total RNA was extracted from leaves using the RNeasy plant mini kit (Qiagen, Mississauga, ON, Canada) according to the supplier's instructions. After treatment with DNase I (Invitrogen, Carlsbad, CA, U.S.A.), first-strand cDNA synthesis was generated using SuperScript II reverse transcriptase (Invitrogen) and the $(\mathrm{dT})_{17} \mathrm{VN}$ oligo in the presence of $0.4 \mathrm{U}$ of RNasin (Fisher Scientific, Pittsburg). The newly synthesized cDNA was diluted

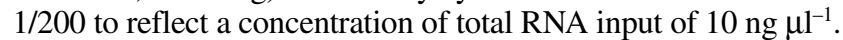

k-RT-PCR was performed on an MX3000 spectrofluorometric thermal cycler (Stratagene, La Jolla, CA, U.S.A.) using a two-temperature cycling regime initiated with a 15-min activation at $95^{\circ} \mathrm{C}$, followed by 40 cycles of 2 min of annealing and extension at $66^{\circ} \mathrm{C}$ and $10 \mathrm{~s}$ of denaturation at $95^{\circ} \mathrm{C}$. Each assay contained 0.5 pmol oligonucleotides (listed in Supplementary Table S2), $5 \mathrm{ng}$ of cDNA, and 1× SYBR Green (Quantitech, Qiagen), prepared as described by Rutledge and Stewart (2008). The fluorescence data collected at the end of each PCR cycle was analyzed by absolute quantification via the cycle threshold method (Rutledge and Stewart 2008). Values were normalized against UBIQUITIN5.

\section{ACKNOWLEDGMENTS}

This research was supported by the National Research Council of Canada Plant Biotechnology Institute (NRC-PBI) core funding (P. R. Fobert), the NRC Genomics and Health Initiative (P. R. Fobert), the National Science and Engineering Research Council of Canada (NSERC) Discovery Grants program (P. R. Fobert, C. Després, and X. Li), Canadian Foundation for Innovation (X. Li), the Michael Smith Laboratories (X. Li), the Chinese National Science Foundation (Y. Zhang), and an NSERC Visiting Scientist in a Government Laboratory Fellowship (H. L. Shearer). This is NRCC publication 50152. We thank the Arabidopsis Biological Resource Center for mutant seed; R. Cameron (McMaster University, Hamilton, ON, Canada) and D. Desveaux (University of Toronto, Toronto, ON, Canada), for providing $P$. syringae pv. tomato DC3000 strains and $P$. syringae pv. maculicola ES4326, respectively; M. Anderson, C. DeLong, C. Chubak, L. Shen, and K. Boyle for technical assistance; the DNA Technology Unit at the NRC-PBI for oligonucleotide synthesis and DNA sequencing; and Y. Wei, P. Polowick, and Y. Pan for their helpful comments on the manuscript.

\section{LITERATURE CITED}

Alonso, J. M., Stepanova, A. N., Leisse, T. J., Kim, C. J., Chen, H., Shinn, P., Stevenson, D. K., Zimmerman, J., Barajas, P., Cheuk, R., Gadrinab, C., Heller, C., Jeske, A., Koesema, E., Meyers, C. C., Parker, H., Prednis, L., Ansari, Y., Choy, N., Deen, H., Geralt, M., Hazari, N., Hom, E., Karnes, M., Mulholland, C., Ndubaku, R., Schmidt, I., Guzman, P., Aguilar-Henonin, L., Schmid, M., Weigel, D., Carter, D. E., Marchand, T., Risseeuw, E., Brogden, D., Zeko, A., Crosby, W. L., Berry, C. C., and Ecker, J. R. 2003. Genome-wide insertional mutagenesis of Arabidopsis thaliana. Science 301:653-657.

Blanco, F., Salinas, P., Cecchini, N. M., Jordana, X., Van Hummelen, P., Alvarez, M. E., and Holuigue, L. 2009. Early genomic response to salicylic acid in Arabidopsis. Plant Mol. Biol. 70:79-102.

Cao, H., Bowling, S. A., Gordon, A. S., and Dong, X. 1994. Characterization of an Arabidopsis mutant that is nonresponsive to inducers of systemic acquired resistance. Plant Cell 6:1583-1592.

Cao, H., Glazebrook, J., Clarke, J. D., Volko, S., and Dong, X. 1997. The Arabidopsis NPRl gene that controls systemic acquired resistance encodes a novel protein containing ankyrin repeats. Cell 88:57-63.
Chisholm, S. T., Coaker, G., Day, B., and Staskawicz, B. J. 2006. Hostmicrobe interactions: Shaping the evolution of the plant immune response. Cell 124:803-814.

Choi, J., Hun, S. U., Kojima, M., Sakakibara, H., Paek, K.-H., and Hwang, I. 2010. The cytokinin-activated transcription factor ARR2 promotes plant immunity via TGA3/NPR1-dependent salicylic acid signaling in Arabidopsis. Dev. Cell. 19:284-295.

Chuang, C. F., Running, M. P., Williams, R. W., and Meyerowitz, E. M. 1999. The PERIANTHIA gene encodes a bZIP protein involved in the determination of floral organ number in Arabidopsis thaliana. Genes Dev. 13:334-344.

Clarke, J. D., and Zhou, T. 2006. Microarray analysis of the transcriptome as a stepping stone towards understanding biological systems: Practical considerations and perspectives. Plant J. 45:630-650.

Clarke, J. D., Liu, Y., Klessig, D. F., and Dong, X. 1998. Uncoupling PR gene expression from NPR1 and bacterial resistance: Characterization of the dominant Arabidopsis cpr6-1 mutant. Plant Cell 10:557-569.

Clough, S. J., and Bent, A. F. 1998. Floral dip: A simplified method for Agrobacterium-mediated transformation of Arabidopsis thaliana. Plant J. 16:735-743.

Després, C., DeLong, C., Glaze, S., Liu, E., and Fobert, P. R. 2000. The Arabidopsis NPR1/NIM1 protein enhances the DNA binding activity of a subgroup of the TGA family of bZIP transcription factors. Plant Cell 12:279-290.

Després, C., Chubak, C., Rochon, A., Clark, R., Bethune, T., Desveaux, D., and Fobert, P. R. 2003. The Arabidopsis NPR1 disease resistance protein is a novel cofactor that confers redox regulation of DNA binding activity to the basic domain/leucine zipper transcription factor TGA1. Plant Cell 15:2181-2191.

Durrant, W. E., and Dong, X. 2004. Systemic acquired resistance. Annu. Rev. Phytopathol. 42:185-209.

Ekengren, S. K., Liu, Y., Schiff, M., Dinesh-Kumar, S. P., and Martin, G. B. 2003. Two MAPK cascades, NPR1, and TGA transcription factors play a role in Pto-mediated disease resistance in tomato. Plant J. 36:905-917.

Foley, R. C., and Singh, K. B. 2004. TGA5 acts as a positive and TGA4 acts as a negative regulator of ocs element activity in Arabidopsis roots in response to defence signals. FEBS (Fed. Eur. Biochem. Soc.) Lett. 563:141-145.

Glazebrook, J., Rogers, E. E., and Ausubel, F. M. 1996. Isolation of Arabidopsis mutants with enhanced disease susceptibility by direct screening. Genetics 143:973-982.

Hellens, R. P., Edwards, E. A., Leyland, N. R., Bean, S., and Mullineaux, P. M. 2000. pGreen: A versatile and flexible binary Ti vector for Agrobacterium-mediated plant transformation. Plant Mol. Biol. 42:819-832.

Hepworth, S. R., Zhang, Y., McKim, S., Li, X., and Haughn, G. W. 2005. BLADE-ON-PETIOLE-dependent signaling controls leaf and floral patterning in Arabidopsis. Plant Cell 17:1434-1448.

Jagadeeswaran, G., Raina, S., Acharya, B. R., Maqbool, S. B., Mosher, S L., Appel, H. M., Schultz, J. C., Klessig, D. F., and Raina, R. 2007. Arabidopsis GH3-LIKE DEFENSE GENE 1 is required for accumulation of salicylic acid, activation of defense responses and resistance to Pseudomonas syringae. Plant J. 51:234-246.

Johnson, C., Boden, E., and Arias, J. 2003. Salicylic acid and NPR1 induce the recruitment of trans-activating TGA factors to a defense gene promoter in Arabidopsis. Plant Cell 15:1846-1858.

Jones, J. D., and Dangl, J. L. 2006. The plant immune system. Nature 444:323-329

Kalde, M., Nühse, T. S., Findlay, K., and Peck, S. C. 2007. The syntaxin SYP132 contributes to plant resistance against bacteria and secretion of pathogenesis-related protein 1. Proc. Natl. Acad. Sci. U.S.A. 104:1185011855 .

Katagiri, F., Lam, E., and Chua, N. H. 1989. Two tobacco DNA-binding proteins with homology to the nuclear factor CREB. Nature 340:727730.

Kesarwani, M., Yoo, J., and Dong, X. 2007. Genetic interactions of TGA transcription factors in the regulation of pathogenesis-related genes and disease resistance in Arabidopsis. Plant Physiol. 144:336-346.

Kim, H. S., and Delaney, T. P. 2002. Over-expression of TGA5, which encodes a bZIP transcription factor that interacts with NIM1/NPR1, confers SAR-independent resistance in Arabidopsis thaliana to Peronospora parasitica. Plant J. 32:151-163.

Kinkema, M., Fan, W., and Dong, X. 2000. Nuclear localization of NPR1 is required for activation of $P R$ gene expression. Plant Cell 12:23392350.

Lebel, E., Heifetz, P., Thorne, L., Uknes, S., Ryals, J., and Ward, E. 1998. Functional analysis of regulatory sequences controlling $P R-1$ gene expression in Arabidopsis. Plant J. 16:223-233.

Li, X., Clarke, J. D., Zhang, Y., and Dong, X. 2001. Activation of an EDS1-mediated R-gene pathway in the sncl mutant leads to constitu- 
tive, NPR1-independent pathogen resistance. Mol. Plant-Microbe Interact. 14:1131-1139.

Lindermayr, C., Sell, S., Müller, B., Leister, D., and Durner, J. 2010. Redox regulation of the NPR1-TGA1 system of Arabidopsis thaliana by nitric oxide. Plant Cell 22:2894-2907.

Liu, G., Holub, E. B., Alonso, J. M., Ecker, J. R., and Fobert, P. R. 2005. An Arabidopsis NPR1-like gene, NPR4, is required for disease resistance. Plant J. 41:304-318.

McDowell, J. M., Cuzick, A., Can, C., Beynon, J., Dangl, J. L., and Holub, E. B. 2000. Downy mildew (Peronospora parasitica) resistance genes in Arabidopsis vary in functional requirements for NDR1, EDS1, NPR1 and salicylic acid accumulation. Plant J. 22:523-529.

Mou, Z., Fan, W., and Dong, X. 2003. Inducers of plant systemic acquired resistance regulate NPR1 function through redox changes. Cell 113:935-944.

Murmu, J., Bush, M. J., Delong, C., Li, S., Xu, M., Khan, M., Malcolmson, C., Fobert, P. R., Zachgo, S., and Hepworth, S. R. 2010. Arabidopsis bZIP transcription factors TGA9 and TGA10 interact with floral glutaredoxins ROXY1 and ROXY2 and are redundantly required for anther development. Plant Physiol. 154:1492-1504.

Nobuta, K., Okrent, R. A., Stoutemyer, M., Rodibaugh, N., Kempema, L., Wildermuth, M. C., and Innes, R. W. 2007. The GH3 acyl adenylase family member PBS3 regulates salicylic acid-dependent defense responses in Arabidopsis. Plant Physiol. 144:1144-1156.

Pan, Y., Pylatuik, J. D., Ouyang, J., Famili, A. F., and Fobert, P. R. 2004. Discovery of functional genes for systemic acquired resistance in Arabidopsis thaliana through integrated data mining. J. Bioinf. Comput. Biol. 2:639-655.

Provart, N., and Zhu, T. 2003. A browser-based functional classification superviewer for Arabidopsis genomics. Curr. Comput. Mol. Biol. 2003:271-272.

Rairdan, J. G., and Delaney, T. P. 2002. Role of salicylic acid and NIM1/NPR1 in race-specific resistance in Arabidopsis. Genetics 161:803-811.

Robert-Seilaniantz, A., Grant, M., and Jones, J. D. G. 2011. Hormone crosstalk in plant disease and defense: More than just JASMONATESALICYLATE antagonism. Annu. Rev. Phytopathol. 49:317-343.

Robinson, S. J., and Parkin, I. A. P. 2008. Differential SAGE analysis in Arabidopsis uncovers increased transcriptome complexity in response to low temperature. BMC Genomics 9:434.

Rochon, A., Boyle, P., Wignes, T., Fobert, P. R., and Després, C. 2006. The coactivator function of Arabidopsis NPR1 requires the core of its $\mathrm{BTB} / \mathrm{POZ}$ domain and the oxidation of C-terminal cysteines. Plant Cell 18:3670-3685.

Rogers, E. E., and Ausubel, F. M. 1997. Arabidopsis enhanced disease susceptibility mutants exhibit enhanced susceptibility to several bacterial pathogens and alterations in $P R-1$ gene expression. Plant Cell 9:305316.

Rutledge, R. G., and Stewart, D. 2008. A kinetic-based sigmoidal model for the polymerase chain reaction and its application to high-capacity absolute quantitative real-time PCR. BMC Biotechnol. 8:47.

Ryals, J., Neuenschwander, U. H., Willits, M. G., Molina, A., Steiner, H. Y., and Hunt, M. 1996. Systemic acquired resistance. Plant Cell 8:1809-1819.

Ryals, J., Weymann, K., Lawton, K., Friedrich, L., Ellis, D., Steiner, H. Y.,
Johnson, J., Delaney, T. P., Jesse, T., Vos, P., and Uknes, S. 1997. The Arabidopsis NIM1 protein shows homology to the mammalian transcription factor inhibitor I $\kappa B$. Plant Cell 9:425-439.

Shearer, H., Wang, L., DeLong, C., Després, C., and Fobert, P. R. 2009. NPR1 enhances the DNA binding activity of the Arabidopsis bZIP transcription factor TGA7. Botany 87:561-570.

Song, Y. H., Song, N. Y., Shin, S. Y., Kim, H. J., Yun, D. J., Lim, C. O., Lee, S. Y., Kang, K. Y., and Hong, J. C. 2008. Isolation of CONSTANS as a TGA4/OBF4 interacting protein. Mol. Cells 25:559-565.

Tada, Y., Spoel, S. H., Pajerowska-Mukhtar, K., Mou, Z., Song, J., Wang, C., Zuo, J., and Dong, X. 2008. Plant immunity requires conformational charges of NPR1 via S-nitrosylation and thioredoxins. Science 321:952-956.

Vanacker, H., Lu, H., Rate, D. N., and Greenberg, J. T. 2001. A role for salicylic acid and NPR1 in regulating cell growth in Arabidopsis. Plant J. 28:209-216.

Vlot, A. C., Dempsey, D. A., and Klessig, D. F. 2009. Salicylic acid, a multifaceted hormone to combat disease. Annu. Rev. Phytopathol. 47:177-206.

Wang, D., Weaver, N. D., Kesarwani, M., and Dong, X. 2005. Induction of protein secretory pathway is required for systemic acquired resistance. Science 308:1036-1040.

Wang, D., Amornsiripanitch, N., and Dong, X. 2006. A genomic approach to identify regulatory nodes in the transcriptional network of systemic acquired resistance in plants. PLoS. Pathog. 2:e123.

Zander, M., La, C. S., Lamotte, O., Metraux, J. P., and Gatz, C. 2010. Arabidopsis thaliana class-II TGA transcription factors are essential activators of jasmonic acid/ethylene-induced defense responses. Plant J. 61:200-210.

Zhang, Y., Fan, W., Kinkema, M., Li, X., and Dong, X. 1999. Interaction of NPR1 with basic leucine zipper protein transcription factors that bind sequences required for salicylic acid induction of the $P R-1$ gene. Proc. Natl. Acad. Sci. U.S.A. 96:6523-6528.

Zhang, Y., Goritschnig, S., Dong, X., and Li, X. 2003a. A gain-of-function mutation in a plant disease resistance gene leads to constitutive activation of downstream signal transduction pathways in suppressor of $n p r 1-1$, constitutive 1. Plant Cell 15:2636-2646.

Zhang, Y., Tessaro, M. J., Lassner, M., and Li, X. 2003b. Knockout analysis of Arabidopsis transcription factors TGA2, TGA5, and TGA6 reveals their redundant and essential roles in systemic acquired resistance. Plant Cell 15:2647-2653.

Zhou, J. M., Trifa, Y., Silva, H., Pontier, D., Lam, E., Shah, J., and Klessig, D. F. 2000. NPR1 differentially interacts with members of the TGA/OBF family of transcription factors that bind an element of the $P R-1$ gene required for induction by salicylic acid. Mol. Plant-Microbe Interact. 13:191-202.

Zipfel, C., Robatzek, S., Navarro, L., Oakeley, E. J., Jones, J. D. G., and Boller, T. 2004. Bacterial disease resistance in Arabidopsis through flagellin perception. Nature 428:764-767.

\section{AUTHOR-RECOMMENDED INTERNET RESOURCE}

The Bio-Array Resouce classification tool: www.bar.utoronto.ca 